\title{
Bamboo Fibers Elaborating Cellulose Hydrogel Films for Medical Applications
}

\author{
Karla Lizette Tovar-Carrillo ${ }^{1,2}$, Motohiro Tagaya ${ }^{1}$, Takaomi Kobayashi ${ }^{1}$ \\ ${ }^{1}$ Department of Materials Science and Technology, Nagaoka University of Technology, Nagaoka, Japan \\ ${ }^{2}$ Instituto de Ciencias Biomédicas, Universidad Autónoma de Cd. Juarez, Juarez, Mexico \\ Email: takaomi@nagaokaut.ac.jp
}

Received October 18, 2013; revised November 18, 2013; accepted November 25, 2013

Copyright (C) 2013 Karla Lizette Tovar-Carrillo et al. This is an open access article distributed under the Creative Commons Attribution License, which permits unrestricted use, distribution, and reproduction in any medium, provided the original work is properly cited. In accordance of the Creative Commons Attribution License all Copyrights (C) 2013 are reserved for SCIRP and the owner of the intellectual property Karla Lizette Tovar-Carrillo et al. All Copyright (C) 2013 are guarded by law and by SCIRP as a guardian.

\begin{abstract}
Bamboo fibers were used as source to prepare cellulose hydrogel films for cell cultivation scaffold. The preparation of cellulose solutions was carried out by three different dissolving methods with $\mathrm{NaOH}$-based and $\mathrm{NaOH} / \mathrm{urea}$ aqueous solutions and $\mathrm{DMAc} / \mathrm{LiCl}$ solution. Several hydrogel films were elaborated and their properties were compared to evaluate the effect of the dissolving method. It was found that tensile strength of the resultant hydrogel films increased from 21 to $66 \mathrm{~N} / \mathrm{mm}^{2}$ when DMAc/LiCl was used instead of the NaOH/urea solution. The same tendency was observed in the obtained elongation values. Moreover, a remarkable difference in fibroblast cell cultivation was observed in higher cell density, when $\mathrm{DMAc} / \mathrm{LiCl}$ method was used. The obtained results with $\mathrm{DMAc} / \mathrm{LiCl}$ also were seen to be higher than the results for PS dish used as control. However, low cytocompatibility was observed when $\mathrm{NaOH}$ and $\mathrm{NaOH} / \mathrm{urea}$ methods were used. The obtained results showed that hydrogel films elaborated with cellulose solution prepared with DMAc/LiCl method exhibited good cytocompatibility for the cell cultivation scaffold.
\end{abstract}

Keywords: Dissolving Method; Bamboo Fibers; Hydrogel; Cytotoxicity

\section{Introduction}

As reported, scientists have devoted much energy to the development of novel hydrogels for tissue engineering. This has a purpose in natural polymers like cellulose occurring in attractive strategy for producing scaffolds for tissue regeneration [1,2]. More recently, fibroblast compatibility was reported on scaffold hydrogel films prepared from agave tequilana weber bagasse for tissue regeneration [3]. However, little is known about the method for elaborating hydrogel films by using cellulose. It is known that cellulose is the most important renewable resource on the earth. Natural fibers as bamboo can be renewable and cheaper for the preparation of hydrogels [1-5]. However, the dissolution of cellulose without chemical modification or derivation is difficult to achieve because of the stiffness and close chain packing caused by numerous inter-and intra-molecular hydrogen bonds which present in cellulose. Therefore, cellulose still has not reached its potential in many areas for all its availability [6-8]. The most general solvents for dissolving cellulose are unsuitable. More common than not, cellulose needs to be activated or made accessible to be dissolved. In addition, the dissolving methods generate hazardous environmental pollution. Moreover, it was found that chemical modification or derivatization methods might affect the cytotoxicity of the obtained films for medical applications [9-12]. Thus, identifying new solvent systems for cellulose processing would help to reduce these toxicity problems. Some powerful non-derivatizing organic solvents for cellulose have been developed and used for preparing regenerated cellulose films and fibers during the last two decades, such as n-methylmorpholine-n-oxide and ionic liquids [13-15]. In addition to solvents mentioned previously, $\mathrm{NaOH}$-based aqueous systems have been one focus of cellulose solvents research because of they can lead to environmentally friendly, simple, and economic process. Moreover, some limitations of $\mathrm{NaOH}$-based aqueous systems have been observed on the preparation of solutions from wood pulps [16-18]. This due to the intermolecular hydrogen bonds presenting in cellulose. The effectively destruction of intermolecular hydrogen bonding, is essential for suc- 
cessful applications of cellulose. Intermolecular hydrogen bonding of polysaccharides can be broken by using urea. Interestingly, $\mathrm{NaOH}$ and especially urea broke intermolecular hydrogen bondings of polysaccharides, loading to enhance water-solubility. The addition of organic compounds such as urea, thiourea to $\mathrm{NaOH}$ solution could have substantial impact on cellulose solubility [19-21].

One of the most useful solvent systems to emerge over the last two dacates is $N, N$-dimethyl acetamide with lithium chloride (DMAc/LiCl). DMAc/LiCl has become the solvent of choice for high-molecular weight cellulose analysis, as well as for the determination of solution characteristics of a number of other polysaccharides [22-24].

The purpose of this study was to compare the preparation method of cellulose solutions from bamboo fibers by $\mathrm{NaOH}$-based aqueous, $\mathrm{NaOH} /$ urea and $\mathrm{DMAc} / \mathrm{liCl}$ systems to elaborate hydrogel films for fibroblast cell cultivation.

\section{Experimental Procedure}

\subsection{Materials}

Bamboo fibers were provided from Hokuetsu Kishu Paper Mill CO. Sodium hydroxide and urea were purchased from TCI (Tokyo, Japan). N,N-dimethyl acetamide was purchased from TCI (Tokyo, Japan) and stored for more than 5 days over potassium hydroxide before uses. Lithium chloride was dried at $80^{\circ} \mathrm{C}$ for $12 \mathrm{~h}$ in a vacuum oven. Ethanol was purchased from Nacalai Tesque. Inc (Tokyo, Japan). Tripsin-M-ethylenediaminetetraacetate (Trypsin-EDTA) was purchased from Gibco (Tokyo, Japan) and formaldehyde (37 vol\% aqueous solution) was from Wako Co., Ltd. NIH3T3 mouse embryonic fibroblast cells were also purchased from BioResource Center (Japan).

\subsection{Preparation of Cellulose Solutions}

$\mathrm{NaOH}-$ based aqueous method: the cellulose fibers $(1 \mathrm{~g})$ were washed and swollen in ethanol followed by water according to exchange solvent technique. Then, cellulose fibers were dissolved in sodium hydroxide aqueous 9 $\mathrm{wt} \%$. The suspension was stirred for $10 \mathrm{~h}$ and then frozen at $-20^{\circ} \mathrm{C}$ to become a solid state. After being frozen in about $15 \mathrm{~h}$, the solid mass was taken out the freezer and thaw at ambient condition [25].

$\mathrm{NaOH} /$ urea method: cellulose fibers $(1 \mathrm{~g})$ were dissolved in urea aqueous solution (14 $\mathrm{wt} \%)$ pre-cooled to $0^{\circ} \mathrm{C}$ with stirring for $1 \mathrm{~min}$. Then, urea aqueous solution (24 $\mathrm{wt} \%$ ) pre-cooled to $0^{\circ} \mathrm{C}$ was added immediately with stirring vigorously for $2 \mathrm{~min}$. The solution was kept at $0^{\circ} \mathrm{C}$ during $12 \mathrm{~h}$ and left at room temperature until the solution became liquid again [21].
DMAc/LiCl method: cellulose fibers $(1 \mathrm{~g})$ were treated by three steps of solvent exchange. First, fibers were suspended in $300 \mathrm{~mL}$ of distilled water and stirred overnight, after water was removed, ethanol $(300 \mathrm{~mL})$ was added to the swelled fibers and the mixture was stirred for $24 \mathrm{~h}$. Then, ethanol was removed and DMAc was added and then stirred for $24 \mathrm{~h}$. Then, DMAc (previously dried with potassium hydroxide) was added to the swelled cellulose fibers to obtain $1 \mathrm{wt} \%$ solution, and $\mathrm{LiCl}(6 \mathrm{wt} \%)$ was added. The mixture was stirred at room temperature for 3 days until a viscous solution was obtained [15].

\subsection{Preparation of Hydrogel Films}

$\mathrm{NaOH}-$ based aqueous method: the obtained solution (10 g) was cast on the glass plate and heated at $70^{\circ} \mathrm{C}$. Then, distilled water was poured into the glass plate to gently wash the semi-membrane obtained and reduce the alkaline and remove the insoluble cellulose. After washing, a second drying process was carried out at $75^{\circ} \mathrm{C}$ until a dried membrane was obtained. Second washing step was done to enhance the mechanical properties. Finally, a third drying step was carried out at $75^{\circ} \mathrm{C}$ until a dried membrane was obtained.

$\mathrm{NaOH} /$ urea aqueous method: the obtained solution (10 g) was poured on a glass plate and coagulated with isopropanol overnight. The resulting film was washed by ethanol 3 times.

DMAc/LiCl method: $10 \mathrm{~g}$ of cellulose solution were poured into a glass plate tray $(10 \mathrm{~cm}$ diameter $)$ and kept for $12 \mathrm{~h}$ in a container filled with $20 \mathrm{~mL}$ of ethanol as coagulant. The resulting film was washed by ethanol 3 times and then submerged in water for $12 \mathrm{~h}$.

The films obtained for the different dissolving methods were submerged in $100 \mathrm{~mL}$ of distilled water and placed in a shaking bath at $25^{\circ} \mathrm{C}$ for $24 \mathrm{~h}$ to remove traces of chemical compounds, distilled water was changed each 2 h. Finally, the hydrogel films were immersed in distilled water for $12 \mathrm{~h}$ and kept in phosphate buffered saline (PBS) at $4^{\circ} \mathrm{C}$ in a plastic container.

\subsection{Evaluation of Hydrogel Films}

Before the preparation of the hydrogel films, shear viscosity of the obtained cellulose solutions was measured by a $\mathrm{B}$ type viscometer at $25^{\circ} \mathrm{C}$. Water contents of the resultant hydrogel films were determined by weighing the wet and dry samples by following. Samples of $5 \mathrm{~mm}$ diameter were cut from cast films, dried in a vacuum oven and weighed. The samples were then swollen in PBS for $36 \mathrm{~h}$ and blotted lightly with filter paper to remove excess PBS. The weight of the swelled samples was then determined. The percent of equilibrium water content (EWC) was calculated based on EWC $=\mathrm{W}_{\mathrm{h}}$ $\mathrm{W}_{\mathrm{d}} / \mathrm{W}_{\mathrm{h}} \times 100$. Where $\mathrm{W}_{\mathrm{h}}$ is the weight of the hydrated 
sample and $\mathrm{W}_{\mathrm{d}}$ is the dry weight of the sample. For each specimen, four independent measurements were determined and averaged [26].

Tensile strength and elongation of the hydrogel films were measured on LTS-500-S20 (Minebea, Japan) with universal testing machine equipped with a $2.5 \mathrm{kN}$ cell. Strips $(50 \times 10 \times 1 \mathrm{~mm})$ were cut from cast films with a razor blade. Strain was recorded by means of ZwickMakrosense clip-on displacement sensors. One set of samples (five strips each) was measured and each set was repeated 3 times. Only samples which ruptured near midspecimen length were considered for calculation of tensile strength. The values of the tensile strength and elongation were calculated by using the following:

Tensile strength $\left(\mathrm{N} / \mathrm{mm}^{2}\right)=$ Maxilum Load/cross-section area.

Elongation $(\%)=($ Final length $(\mathrm{mm})-$ Initial length $(\mathrm{mm})) /($ Initial length $(\mathrm{mm})) \times 100$

Water contact angle (WCA) measurements were carried out by using a contact angle goniometer (Kyowa Interface Science). Samples of $2 \times 2 \mathrm{~cm}$ were cut from cast films. Samples were stuck on a glass slide and mounted on the goniometer. A total of $3 \mu \mathrm{L}$ of distilled water was dropped on the airside surface of the film at room temperature. And the values of the contact angle were measured after 10 seconds and at least eight measurements were averaged for each prepared film to obtain a reliable value.

\subsection{Cytotoxicity of Hydrogel Films}

Hydrogel films circles with $30 \mathrm{~mm}$ diameter were used for cell seeding purposes. The samples were sterilized with 70 and $50 \mathrm{wt} \%$ of aqueous ethanol for $30 \mathrm{~min}$ and then, rinsed twice with PBS for $30 \mathrm{~min}$. Finally, the hydrogel films were swelled in Dulbecco's modified eagle medium (DMEM) for $2 \mathrm{~h}$ before seeding procedure. The NIH3T3 mouse embryonic fibroblast cells were cultured at $37^{\circ} \mathrm{C}$ in $95 \mathrm{wt} \%$ of relative humidity and $5 \mathrm{wt} \%$ of $\mathrm{CO}_{2}$ environment. The culture medium was in $90 \mathrm{wt} \%$ of DMEM supplemented with $10 \mathrm{wt} \%$ of fetal bovine serum (FBS) and $1 \mathrm{wt} \%$ of penicillin/streptomycin. The cells were seeded (cell density $8 \times 10^{3} \mathrm{~cm}^{2}$ ) on the hydrogel films and tissue culture grade polystyrene dish (PS dish) was used as control. The cells were used for imaging and characterization purpose after $4,24,48$ and $72 \mathrm{~h}$ of culture. The sample image was obtained using an inverse microscope (Olympus CKX41, Japan). Approximately, 50 cells were analyzed per image. For each sample, five images were analyzed to obtain an unbiased estimated of the cell morphology. The results presented herein were based on three independent experimental runs. The measurements were assessed statically using a one-way analysis of variance (ANOVA) test followed by Student's t Test with a significance criterion of $p<0.05$.

\section{Results and Discussion}

\subsection{Preparation of Hydrogel Films}

Figure 1 shows shear viscosity of the obtained cellulose solutions. The white cellulose fibers from bamboo were used (Figure 2(a)). The cellulose solutions made with bamboo fibers varying the dissolving method showed a significant difference in shear viscosity value around 107 $\mathrm{Cp}, 109 \mathrm{Cp}$, and 165Cp for $\mathrm{NaOH}$-based aqueous method, $\mathrm{NaOH} /$ urea aqueous method and DMAc/LiCl method, respectively. The change could be attributed to the effect on the cellulose fibers by the chemical compounds used in the different methods. McCormick et al., reported that compounds such as sodium hydroxide tend to affect changes in the molecule: the remaining cellulose is either degraded, its crystallinity has been altered and/or it is not absolutely pure [27]. It was also observed that shear viscosity value was higher in the cellulose solution prepared by $\mathrm{DMAc} / \mathrm{LiCl}$ method. This could be due to it has been reported that the $\mathrm{DMAc} / \mathrm{LiCl}$ method can dissolved cellulose with a molecular weight of more than $10^{6}$ under ambient conditions without severe degradation or other undesirable reaction.

It was seen that a remarkable difference in appearance was observed in the obtained hydrogel films. All the cellulose solutions prepared from bamboo fibers (Figure 2(a)) by different dissolving method were transparent. On the other hand, the hydrogel film elaborated with cellulose fibers dissolved by $\mathrm{NaOH} /$ Urea method showed a white color and low transparency (Figure 2(b)). Lower white color was observed in hydrogel film prepared with cellulose fibers dissolved by $\mathrm{NaOH}$-based aqueous method (Figure 2(c)). In addition, only a highly trans- parent and color less hydrogel film was obtained when DMAc/LiCl method was used for the preparation of cellulose solution (Figure 2(d)).

Table 1 also lists hydrogel film properties, as equilibrium water content at room temperature for $36 \mathrm{~h}$.

The water content decreased from $31.2 \%$ to $10.9 \%$ when the dissolving method was change from DMAc/ $\mathrm{LiCl}$ to $\mathrm{NaOH} /$ urea for the preparation al cellulose solution. This could be attributed the effect of $\mathrm{NaOH}$ on the cellulose fibers. Thus, when $\mathrm{DMAc} / \mathrm{LiCl}$ method was used for the preparation of cellulose solution, water molecules were capable of penetrating and interacted easily into the obtained hydrogel films. For uniaxial tensile testing, the hydrogel samples $(50 \times 10 \times 1 \mathrm{~mm})$ were placed between two clamps and the film was then pulled away. Table 1 shows that higher elongation and tensile strength was observed in the films elaborated with cellulose solution prepared with $\mathrm{DMAc} / \mathrm{LiCl}$ method. Tensile and elongation values increased from 21 to $66 \mathrm{~N} / \mathrm{mm}^{2}$ and from $8 \%$ to $33.5 \%$, in the cases of $\mathrm{NaOH} /$ urea and $\mathrm{DMAc} / \mathrm{LiCl}$, respectively. Water contact measurements 


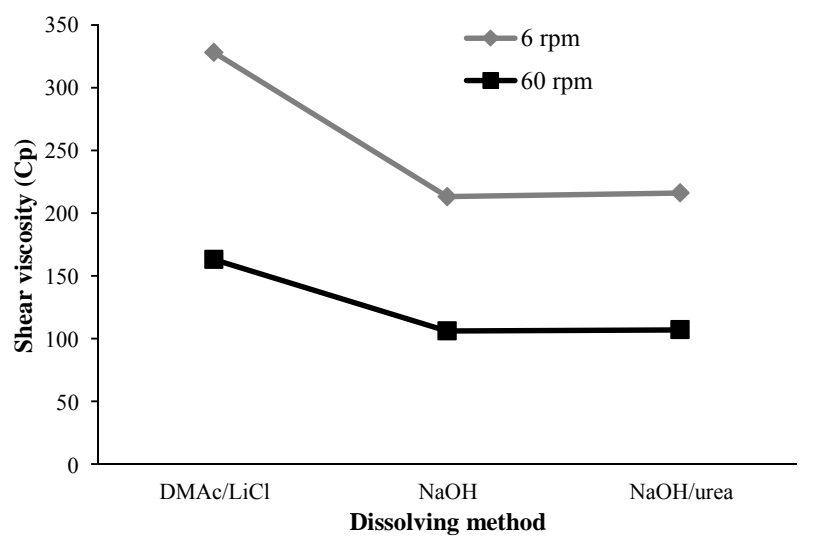

Figure 1. Shear viscosity of hydrogel films elaborated with cellulose solution prepared with different dissolving method. Shear viscosity was measured at 6 and $60 \mathrm{rpm}$ at $25^{\circ} \mathrm{C}$.
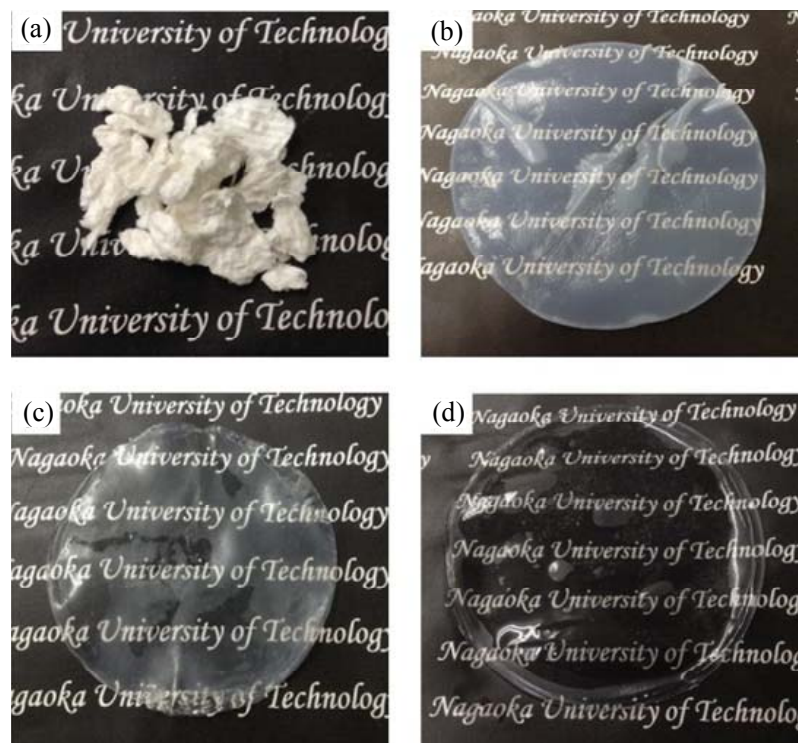

Figure 2. Cellulose fibers and hydrogel films for (a) bamboo fibers, (b) film obtained when $\mathrm{NaOH} / \mathrm{urea}$ and, (c) film obtained when $\mathrm{NaOH}$ method, were used and (d) for film obtained when DMAc/LiCl was used.

Table 1. Properties of hydrogel films.

\begin{tabular}{ccccc}
\hline $\begin{array}{c}\text { Dissolving } \\
\text { method }\end{array}$ & $\begin{array}{c}\text { EWC } \\
(\%)\end{array}$ & $\begin{array}{c}\text { Elongation } \\
(\%)\end{array}$ & $\begin{array}{c}\text { Tensile strength } \\
\left(\mathrm{N} / \mathrm{mm}^{2}\right)\end{array}$ & $\begin{array}{c}\text { WCA } \\
(\text { degree })\end{array}$ \\
\hline $\mathrm{DMAc} / \mathrm{LiCl}$ & 31.2 & 33.5 & 66 & 61 \\
$\mathrm{NaOH}$ & 14.1 & 13 & 27 & 35 \\
$\mathrm{NaOH} / \mathrm{urea}$ & 10.9 & 8 & 21 & 32 \\
\hline
\end{tabular}

showed that the surface of films obtained with cellulose solutions prepared with $\mathrm{NaOH}$ were more hydrophilic with a contact angle around $32^{\circ}$ compared with the hydrophilic behave observed on the surface of hydrogel films elaborated with cellulose solution prepared with DMAc/ $\mathrm{LiCl}$ with contact value around $61^{\circ}$.

\subsection{Cytotoxicity of Hydrogel Films}

If the present hydrogels would be applied for healing repair as scaffold, another important issue to consider is fibroblast growing on the hydrogel surface [3]. In order to observe such behavior, phase-contrast light microscope images were used. Figure 3 shows cell density of the hydrogel films prepared.

A remarkable difference was observed when the dissolving method for the preparation of cellulose solutions was changed (ANOVA, $p<0.05$ ). Moreover, the number of adherent cells on the hydrogel films was higher when $\mathrm{DMAc} / \mathrm{LiCl}$ was used, this was significant (Student's $\mathrm{t}$-test, $p<0.05, \mathrm{n}=6$ ). This results were significant comparing $\mathrm{NaOH}$ and $\mathrm{NaOH} /$ Urea method (Student's t-test, $p$ $<0.05, \mathrm{n}=6$ ). After $72 \mathrm{~h}$ of cultivation cell density on hydrogel films elaborated with cellulose solution prepared with $\mathrm{DMAc} / \mathrm{LiCl}$ method showed an increased. This increase was significant comparing with PS dish results (Student's t-test, $p<0.05, \mathrm{n}=6$ ). These results were consistent with the reported by Salem, et al., they observed higher cell density on surface with a contact angle around $60^{\circ}[28]$ as the observed on hydrogel films elaborated with cellulose solution prepared with DMAc/ $\mathrm{LiCl}$ method.

As shown in Figure 4, phase-contrast light microscope images revealed a remarkable difference on fibroblast pattern in the morphology for PS dish (a-c) used as control, and the hydrogel films (d-1).The Hydrogel films obtained in the DMAc/ $\mathrm{LiCl}$ system was used for cases of (d-f). The adherent cells showed longer axis shape of the grown adherent cells as compared with those adhered on the PS dish at the same condition (a-c). Moreover, the boundaries of the adherent cells on the cellulose films obtained when $\mathrm{DMAc} / \mathrm{LiCl}$ method was seemed to be clear tightly adhesion at $4 \mathrm{~h}$ for (d) on the hydrogel surface showing a diffuse shape on the cultivated cell edge. In addition, anisotropic shape was observed in the first 4 $\mathrm{h}$ of cell culture. It was also noticed that the anisotropic shape increased in the adherent fibroblast cells after $72 \mathrm{~h}$ (d) of culture time passed [3]. These results revealed that the hydrogel films obtained from $\mathrm{DMAc} / \mathrm{LiCl}$ solution had higher cytocompatibility ratherthan the PS dish used. On the other hand, the cellulose obtained in the $\mathrm{NaOH}$ method was used as (g-i) adherent fibroblast cells showed lower anisotropic shape as compared to PS dish at $4 \mathrm{~h}$. In addition, no significant difference on the number of adherent fibroblast cells and less change in morphology was observed during the $72 \mathrm{~h}$. When the $\mathrm{NaON} /$ urea was used as ( $\mathrm{j}-1)$, the adherent cells had also less anisotropic shape, butround shape was observed at $4 \mathrm{~h}$. The boundaries of the fibroblast cells seemed to show poor adhesion of the cellulose films and to be less remarkable difference in the observed at $72 \mathrm{~h}$. These results showed that the low cytocompatibility of the hy- 


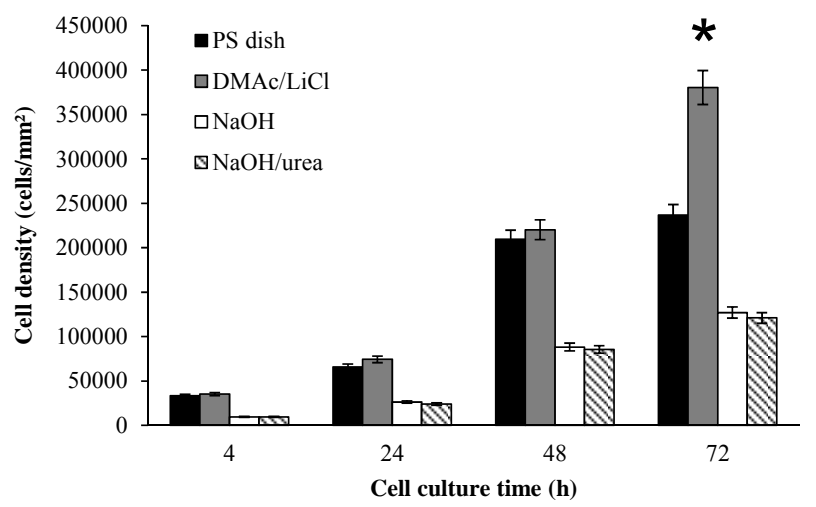

Figure 3. Cell number on the hydrogel films surfaces as function of culture time. The dissolving method for the preparation of cellulose solution was varied. An asterisk indicates statistically significant different from PS dish used as control $(p<0.05)$. Mean $\pm \operatorname{SEM}(n=6)$.

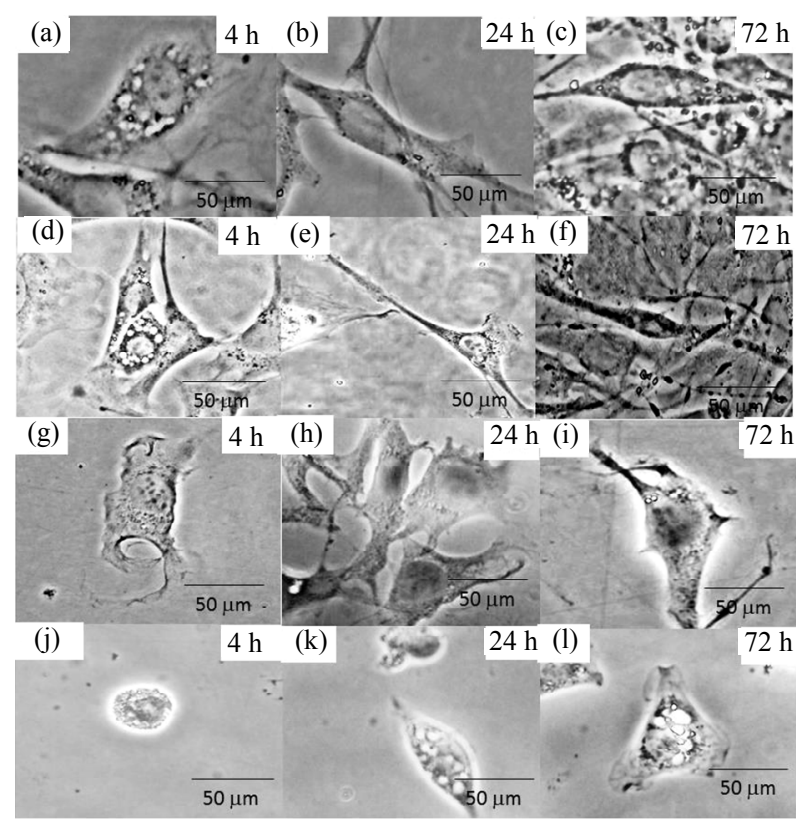

Figure 4. Phase-contrast light images, (a-c) PS dish used as control, (d-f) DMAc/LiCl method, (g-i) NaOH method and (j-l) NaOH/urea method. The time culture was 4, 24 and 72 h.

drogel films obtained by the $\mathrm{NaOH}$ and $\mathrm{NaOH} /$ urea methods. This could be attributed to the lower water attachment rather than the sample surface of the DMAc/ $\mathrm{LiCl}$ for the $\mathrm{NaOH}$ and $\mathrm{NaOH} /$ urea films. It has been reported for the silicon scaffolds that lower contact angle values and low mechanical properties affected fibroblast adhesion [28].

\section{Conclusion}

Cellulose hydrogel films from bamboo fibers dissolved by three different methods were obtained. Depending of the dissolving method used, hydrogel film exhibited lower tensile strength, elongation and contact angle in the case of $\mathrm{NaOH}$ and $\mathrm{NaOH} /$ urea systems. On the other hand, very good cytocompatibility was observed in the hydrogel films elaborated with $\mathrm{DMAc} / \mathrm{LiCl}$ solution. It was proved that the dissolving method used for the preparation of the cellulose solution affects the properties of the obtained films. These results suggest that hydrogel films elaborated with cellulose solution prepared with DMAc/LiCl showed better possibility of usage for tissue engineering scaffold.

\section{REFERENCES}

[1] F. A. Muller, L. Muller, I. Hofman, P, Greil, M. M. Wenzel and R. Staudenmaier, "Cellulose Based Scaffold Materials for Cartilage Tissue Engineering," Biomaterials, Vol. 27, No. 21, 2006, pp. 3955-3963.

http://dx.doi.org/10.1016/j.biomaterials.2006.02.031

[2] H. Hoenich, "Cellulose for Medical Applications: Past, Present, and Future," Bioresources, Vol. 2, No. 2, 2006, pp. 270-280.

[3] K. L. Tovar-Carrillo, M. Tagaya and T. Kobayashi, "Fibroblast Compatibility on Scaffold Hydrogels Prepared from Agave Tequilana Weber Bagasse for Tissue Regeneration," Industrial \& Engineering Chemistry Research, Vol. 52, No. 33, 2013, pp. 11607-11613. http://dx.doi.org/10.1021/ie401793w

[4] W. Deoliveira and W. G. Glasser, "Hydrogels from Polysaccharides. 1. Cellulose Beads for Chromatographic," Journal of Applied Polymer Science, Vol. 60, No. 1, 1996, pp. 63-73.

http://dx.doi.org/10.1002/(SICI)1097-4628(19960404)60: $1<63:$ AID-APP8>3.0.CO;2-T

[5] H. Saito, A. Sakurai, M. Sakakibara and H. Saga, "Preparation and Properties of Transparent Cellulose Hydrogels," Journal of Applied Polymer Science, Vol. 90, No. 11, 2002, pp. 3020-3025. http://dx.doi.org/10.1002/app.13015

[6] S. Zhang, F. X. Li and J. Y, Yu, "Preparation of Cellulose/Chitin Blend Bio-Fibers via Direct Dissolution," Cellulose Chemistry and Technology, Vol. 43, No. 9-10, 2009, pp. 393-398.

[7] C. F. Liu, R. C. Sun, A. P. Zhang and J. L. Ren, "Preparation of Sugarcane Bagasse Cellulosic Phthalate Using an Ionic Liquid as Reaction Medium," Carbohydrate Polymers, Vol. 68, No. 1, 2007, pp. 17-25.

http://dx.doi.org/10.1016/j.carbpol.2006.07.002

[8] M. Abe, Y. Fukaya and H. Ohno, "Fast and Factible Dissolution of Cellulose with Tetrabutylphosphonium Hydroxide Containing $40 \mathrm{wt} \%$ Water," Chemical Communications, Vol. 48, No. 12, 2012, pp. 1808-1810. http://dx.doi.org/10.1039/c2cc16203b

[9] L. Yan and Z. Gao, "Dissolving of Cellulose in PEG/ $\mathrm{NaOH}$ Aqueous Solution," Cellulose, Vol. 15, No. 6, 2008, pp. 789-796. http://dx.doi.org/10.1007/s10570-008-9233-5

[10] J, Vitz, T. Erdmenger, C. Haensch and U. S. Schubert, 
"Extended Dissolution Studies of Cellulose in Imidazolium Based Ionic Liquids," Green Chemistry, Vol. 11, No. 3, 2009, pp. 417-424. http://dx.doi.org/10.1039/b818061j

[11] E. Sjoholm, K. Gustafsson, B. Eriksson, W. Brown and A. Colmjo, "Aggregation of Cellulose in Lithium Chloride/ N,N-dimethylacetamide," Carbohydrate Polymers, Vol. 41, No. 2, 2000, pp. 153-161. http://dx.doi.org/10.1016/S0144-8617(99)00080-6

[12] E. Sjoholm, K, Gustafsson, B. Pettersson and A. Colmsjo, "Characterization of the Cellulosic Residues from Lithium Chloride/N,N-dimethylacetamide Dissolution of Softwood Kraft Pulp," Carbohydrate Polymers, Vol. 32, No. 1, 1997, pp. 57-63. http://dx.doi.org/10.1016/S0144-8617(96)00129-4

[13] A. Ostlund, D. Lundberg, L. Nordstierna, K. Holmberg and M. Nyden, "Dissolution and Gelation of Cellulose in TBAF/DMSO Solutions: The Roles of Fluoride Ions and Water," Biomacromolecules, Vol. 10, No. 9, 2009, pp. 2401-2407. http://dx.doi.org/10.1021/bm900667q

[14] B. Lindman, G. Karlstrom and L. Stigsson, "On the Mechanism of Dissolution of Cellulose," Journal of Molecular Liquids, Vol. 156, No. 1, 2010, pp. 76-81. http://dx.doi.org/10.1016/j.molliq.2010.04.016

[15] A. M. Striegel, "Theory and Applications of DMAc/LiCl in the Analysis of Polysaccharides," Carbohydrate Polymers, Vol. 34, No. 4, 1997, pp. 267-274. http://dx.doi.org/10.1016/S0144-8617(97)00101-X

[16] S. Zhang, F. X. Li, J. Y. Yu and Y. L. Hsieh, "Dissolution Behavior and Solubility If Cellulose in $\mathrm{NaOH}$ Complex Solution," Carbohydrate Polymers, Vol. 81, No. 3, 2010, 668-674. http://dx.doi.org/10.1016/j.carbpol.2010.03.029

[17] A. Isogai and R. H. Atalla, "Dissolution of Cellulose in Aqueous NaOH Solutions," Cellulose, Vol. 5, No. 4, 1995, pp. 309-319. http://dx.doi.org/10.1023/A:1009272632367

[18] S. Zhang, F. X. Li, J. Y. Yu and G. L. Xia, "Dissolved State and Viscosity Properties of Cellulose in a $\mathrm{NaOH}$ Complex Solvent," Cellulose Chemistry and Technology, Vol. 43, No. 9-10, 2009, pp. 241-249.

[19] H. Jin, C. Zha and L. Gu, "Direct Dissolution of Cellulose in $\mathrm{NaOH} /$ Thiourea/Urea Aqueous Solution," Carbohydrate Research, Vol. 342, No. 6, 2007, pp. 851-858. http://dx.doi.org/10.1016/j.carres.2006.12.023

[20] J. Behin, F. Mikanikl and Z. Fadael, "Dissolving Pulp
(Alpha-Cellulose) from Corn Stalk by Kraft Process," Iranian Journal of Chemistry Engineering, Vol. 5, No. 3, 2008, pp. 14-28.

[21] J. Zhou and L. Zhang, "Solubility of Cellulose in $\mathrm{NaOH} /$ Urea Aqueous Solution," Polymer Journal, Vol. 32, No. 10, 2000, pp. 866-870.

[22] L. A. Ramos, D. L. Morgado, O. A. El Seoud, V. C. da Silva and E. Frollini, "Acetylation of Cellulose in LiClN,N-Dimethylacetamide: First Report on the Correlation between the Reaction Effiency and the Aggregation Number of Dissolved Cellulose," Cellulose, Vol. 18, No. 2, 2011, pp. 385-392. http://dx.doi.org/10.1007/s10570-011-9496-0

[23] D. Ishii, D. Tatsumi and T. Matsumoto, "Effect of Solvent Exchange on the Supramolecular Structure, the Molecular Mobility and the Dissolution Behaviour of Cellulose in LiCl/DMAc," Carbohydrate Research, Vol. 343, No. 5, 2008, pp. 919-928. http://dx.doi.org/10.1016/j.carres.2008.01.035

[24] N. G. Wanhg, J. Kim, Y. Chen, S. R. Yun and S. K. Lee, "Electro-Active-Paper Actuator Made with $\mathrm{LiCl} / \mathrm{Cellu}$ lose Films: Effect of LiCl content," Macromolecular Research, Vol. 14, No. 6, 2006, pp. 624-629. http://dx.doi.org/10.1007/BF03218734

[25] H. Qi, Q. Yang, L. Zhang, T. Liebert and T. Heinze, "The Dissolution of Cellulose in NaOH-based Aqueous System by Two-Step Process," Cellulose, Vol. 18, No. 2, 2011, pp. 237-245. http://dx.doi.org/10.1007/s10570-010-9477-8

[26] K. Mequanint, A. Patel and D. Bezuidenhout, "Synthesis, Swelling Behaviour, and Biocompatibility of Novel Physically Cross-Linked Polyurethane-Block-POLY (Glycerol Methacrylate) Hydrogels," Biomacromolecules, Vol. 7, No. 3, 2006, pp. 883-891. http://dx.doi.org/10.1021/bm0507047

[27] T. R. Dawsey and C. L. McCormick, "The Lithium Chloride/Dimethylacetamide Solvent for Cellulose: A Literature Review," Journal of Macromolecular Science, Part C: Polymers Reviews, Vol. 30, No. 3-4, 1990, pp. $405-$ 440. http://dx.doi.org/10.1080/07366579008050914

[28] A. K. Salem, S. J. Tendler, C. J. Roberts, "Interactions of 3T3 Fibroblasts and Endothelial Cells with Defined Pore Features," Journal of Biomedical Materials Research, Vol. 61, No. 2, 2002, pp. 212-217. http://dx.doi.org/10.1002/jbm.10195 